\title{
Kritik Ayak İskemisi Tedavisinde Endovasküler Perkütan Transkateter Balon Anjioplasti Yönteminin Etkinliği
}

\author{
Bekir TURGUT ๑ $₫$ \\ Konya Eğitim ve Araştırma Hastanesi, Sağlık Bilimleri Üniversitesi, Radyoloji Bilim Dalı, Konya, Türkiye
}

Bu makaleye yapılacak atıf: Turgut B. Kritik Ayak İskemisi Tedavisinde Endovasküler Perkütan Transkateter Balon Anjioplasti Yönteminin Etkinliği. Türk Diyab Obez 2020;1: 16-21.

\begin{abstract}
ÖZET
Amaç: Bu çalışmanın amacı periferik arter hastalığı $(\mathrm{PAH})$ bulunan infrapopliteal arterlerde uygulanan perkütan transkateter anjioplasti (PTA) tedavisinin etkinliğini değerlendirmektir.

Gereç ve Yöntemler: Ocak 2018 ve Ocak 2019 tarihleri arasında, infrapopilteal PAH nedeni ile endovasküler PTA tedavisi uygulanan hastaların kayıtlı olan bulguları ve kontrol Doppler ultrasonografi (DUSG) raporları elde edildi. Tedavi öncesi ve tedavi sonrası kayıtlı DSA görüntüleri incelenerek hangi vasküler yapıların hastalıklı olduğu, sayısı ve tedaviye yanıtı listelendi. Kritik ayak iskemisi olan, iskemik dinlenme ağrısı veya ayak yarası olan endovasküler tedavi uygulanmış hastalar çalışmaya dâhil edildi. Endovasküler tedavi teknik başarı kriterlerleri olarak, DSA'da hastalıklı vasküler yapının normal açıklığa ulaşması, kontrast maddenin bu seviye distaline geçişinin yeterli olması olarak belirlendi. Kontrol DUSG uygulamalarda normal formda trifazik alt ekstremite arteryal akım formu olması patensi kriteri olarak belirlendi. İlk tedavi sonrasında, başka endovasküler tedaviye ihtiyaç olmadan bir yıllık süreli açık kalma lma durumu primer patensi olarak kabul edildi. Bu süreçte vasküler açık kalma için ek tedavi ihtiyacı olmuş ise sekonder patensi olarak kabul edildi.

Bulgular: Endovasküler olarak tedavi edilmiş toplamda, 27 infrapopliteal arter hastalığı olan 19 hastanın verileri çalışmaya dâhil edildi. Hastaların $15(\% 78,9)$ 'inde hipertansiyon, dokuzunda $(\% 47,3)$ diyabet ve yedisi $(\% 36,8)$ sigara kullanımı hikayesi mevcuttu. Hastaların \%68,4'inde iskemik cilt ülseri ve \%42'sinde istirahat ağrısı mevcuttu. Tamamında egzersiz ile ortaya çıkan ağrı semptomu oldu. Uygulanan PTA sonrası herhangi bir hastada cerrahi müdahale gerektiren majör komplikasyon olmadı. Bir yıllık primer patensi oranı \%73,6 (14/19), sekonder patensi oranı \%84,2 (16/19) oldu.

Sonuç: İnfrapopliteal PAH tedavisinde endovasküler PTA düşük komplikasyon ve yüksek patensi oranları ile güvenle kullanılabilir.

Anahtar Sözcükler: Kritik ayak iskemisi, Perkütan transkateter balon anjiyoplasti, Periferik arter hastalı̆̆

\section{Efficacy of Endovascular Percutaneous Transcatheter Balloon Angioplasty in the Treatment of Critical Foot Ischemia}

ABSTRACT

Aim: The aim of this study was to evaluate the efficacy of percutaneous transcatheter angioplasty (PTA) in infrapopliteal arteries with peripheral arterial disease (PAH).

Material and Methods: Between January 2018 and January 2019, the recorded findings and control Doppler ultrasonography (DUSG) reports of patients undergoing endovascular PTA treatment for infrapopilteal PAH were obtained. Pre- and post-treatment recorded DSA images were analyzed to list which vascular structures were diseased, their number and response to treatment. Patients who received endovascular treatment due to critical foot ischemia, ischemic resting pain or foot wound were included in the study. The normal clearance of the diseased vascular structure in DSA and the adequate passage of the contrast medium to this level were determined as the technical success criteria of endovascular treatment. In control DUSG applications, a normal form of triphasic lower extremity arterial flow was determined as the patency criterion. After provincial treatment, one-year stay with no endovascular treatment was accepted as primary patency. Secondary patency was considered if additional treatment was needed for vascular exposure during this period.
\end{abstract}

ORCID: Bekir Turgut / 0000-0001-8276-9996 
Results: Data from 19 patients with a total of 27 infrapopliteal artery disease treated endovascularly were included in the study. 15 (78.9\%) patients had hypertension, nine (47.3\%) had diabetes, seven (36.8\%) had smoking history. $68.4 \%$ of patients had ischemic skin ulcers and $42 \%$ had rest pain. There was exercise-induced pain in all of them. There was no major complication requiring surgical intervention in any patient after PTA. One-year primary patency rate was $73.6 \%(14 / 19)$ and secondary patency rate was $84.2 \%(16 / 19)$. Conclusion: Endovascular PTA can be used safely in the treatment of infapopliteal PAH with low complication and high patency rates. Key Words: Critical foot ischemia, Percutaneous transcatheter balloon angioplasty, Peripheral artery disease

\section{GİRIŞ}

Periferik arter hastalığ $1(\mathrm{PAH})$, önemli morbidite ve mortaliteye sahip sistemik bir hastalıktır. Çok sayıda PAH hastasında infrapopliteal vasküler hastalık vardır. Kritik ayak iskemisi, obstrüktif, aterosklerotik, periferik arter hastalığ1nın terminal aşamasını temsil eder (1). Kritik ayak iskemisinden etkilenen hastalar, periferik arter hastalığı olanların en karmaşık alt kümesidir ve tipik olarak hipertansiyon, hiperlipidemi, diabetes mellitus ve böbrek yetmezliğinin uzun vadeli patolojik sonuçlarını taşırlar $(2,3)$.

Hem femoropopliteal hem de diz altı aterosklerotik lezyonlar bypass cerrahisine kıyasla bildirilen 30 günlük düşük morbidite ve mortalite nedeniyle yaygın olarak endovasküler onarım ile tedavi edilmektedir $(4,5)$.

Kritik ayak iskemisi prognozunu hızlı değerlendirme, yara bakımı ve revaskülarizasyonun erken uygulanması etkiler (6). Son on y1lda, kritik ayak iskemisi tedavisinde en önemli değişiklik, ilk tercih revaskülarizasyon teknikleri olarak baypas cerrahisinden invaziv endovasküler prosedürlere geçme eğiliminin artmasıydı. Kritik ayak iskemisi için müdahalenin amaçları arasında, yara iyileşmesine yardımcı olmak, ayağa akımın restorasyonu, dinlenme ağrısının hafifletilmesi, büyük amputasyondan kaçınma, hareketliliğin korunması ve hasta fonksiyonunun ve yaşam kalitesinin iyileştirilmesi yer alır. Değerlendiren hekim, tedavinin hedefleri, risk-fayda oranları, hasta komorbiditeleri ve yaşam beklentilerini göz önünde bulundurarak, en uygun müdahaleyi veya müdahale kombinasyonunu seçmek için tüm revaskülarizasyon seçeneklerinden tamamen haberdar olmalıdır (7). Bu çalışma ve devamında yapılacak yapılacak olan diğer yeni çalışmalar endovasküler tedavinin olumlu sonuçlarının bilinmesine ve değerlendiren hekim tarafından hastaların bu tedaviye daha hızlı yönlendirilmesine katkı sağlayabilir.

$\mathrm{Bu}$ çalışmanın amacı PAH bulunan infrapopliteal arterlerde uygulanan perkütan transkateter anjioplasti (PTA) tedavisinin primer ve sekonder patensi açısından sonuçlarını değerlendirmektir.

\section{GEREÇ ve YÖNTEMLER}

\section{Etik Kurul Onayı}

Çalışmadaki tüm prosedürler insan katılımcılara, ulusal araştırma komitesi standartlarına ve 1964 Helsinki Dekla- rasyonu ve sonraki baskılarına ilişkin etik kurallara uygun olarak yapılmıştır. Bu çalışma yerel etik kurul komitesi tarafindan onaylanmıştır (Etik kurul onay yılı/sayı: 2020/2316).

\section{Çalışma Planı ve Hasta Seçim Kriterleri}

Çalışma kurum Girişimsel Radyoloji ünitesinde retrospektif olarak planlandı. Ocak 2018 ve Ocak 2019 tarihleri arasında dizaltı PAH nedeni ile endovasküler PTA tedavi uygulanan hastaların dosya bilgileri elde edildi. Ayrıca tedavi öncesi ve tedavi sonrası alınan kayıtlı dijital subtraction anjiografi (DSA) görüntüleri incelendi. Dosya bilgileri taranarak demografik veriler ve ek hastalık verileri kayıt edildi. Kayıtlı DSA görüntüleri incelenerek hangi vasküler yapıların hastalıklı olduğu, sayısı ve tedaviye yanıtı listelendi. Kontrollerde uygulanmış olan Doppler ultrasonografi (DUSG) raporları ile takip bulguları elde edildi.

Aynı ekstremitede femoral veya iliak arterlerde darlık veya stenoz bulgusu olan hastalar ve bu nedenle tedavi uygulanmış hastalar çalışma dışında tutuldu. Birincil amputasyon gerektiren ayak bileğini geçerek iskemik ülser olan fonksiyonel olarak kurtarılamaz uzuvlarla başvuran kritik ayak iskemisi hastaları çalışma dışında tutuldu.

Kritik ayak iskemisi olan, iskemik dinlenme ağrısı veya ayak yarası olan endovasküler tedavi uygulanmış hastalar çalışmaya dâhil edildi.

Endovasküler tedavi teknik başarı kriterleri DSA görüntüsünde oklüde veya stenotik bölgenin kontrast madde ile dolumu ve distale geçişinin yeterli olması ve kontrol DUSG uygulamalarda normal formda trifazik alt ekstremite arteryal akım formu olması olarak belirlendi (Şekil 1A,B). Diz altı vasküler tek seans tedavi ile bir yıllık açık kalma durumu primer patensi olarak kabul edildi. Bu süreçte vasküler açık kalma için ek tedavi ihtiyacı olmuş ise sekonder patensi olarak kabul edildi.

\section{Endovasküler Tedavi ve Takip Protokolï}

Tüm hastalara günde bir kez 100 mg asetilsalisilik asit ve birkez $75 \mathrm{mg}$ kolpidogrel oral tablet tedavisi işlemden en az bir hafta öncesinde başlandı.

Tam steril şartlarda USG ve floroskopi cihazı kılavuzluğunda endovasküler tedavi uygulandı. Povidion iyot ile giriş bölgesi sterilizasyonu sağlandıktan sonra ciltaltı lokal anestezik 
uyguland. Bu lokalizasyonda ana femoral arterden antegrad yaklaşım ile 5F introducer sheat yerleştirildi. Proksimalden başlayarak plantar ark düzeyini de kapsayacak şekilde tanısal amaçlı ekstremite dijital subtraction anjiografi (DSA) görüntüleri elde edildi. Anjiografi görüntüleri alma esnasinda her seferinde toplamda $6 \mathrm{cc}$ noniyonik kontrast madde sheat içerisinden bolus olarak verildi. Tedavi kararı verildikten sonra sistematik olarak 5.000 ünite heparin sodyum üst ekstremite ven içi bolusu ile heparinize edilir.

Hastalıklı damar tespit edildi. Oklüzyon veya darlı̆̆ 1 transluminal olarak geçmek için hidrofilik uçlu bir 0.014 $300 \mathrm{~cm}$ hydrophilic kaplamalı kılavuz tel (V-18 Control Wire, Boston Scientific, ABD) kullanıldı. Hastalıklı damar bölgesi kılavuz tel ile geçildikten sonra tel üzerinden oklüde damarı tam kapsayacak şekilde 2-3 mm çaplı ve 20-150 $\mathrm{mm}$ uzunlukta balon kateterler (Sterling, Boston Scientific, ABD) kullanılarak PTA uyglandı. İşlem sonrası DSA ile darlık/oklüde olan kısmın rekanalize olduğu ve ayak tabanı plantar arkta eş zamanlı dolum sağlandığı görüldüğünde tedavi sonlandırıldı (Şekil 2A-D).

Tüm hastalara tedavi sonrasinda 3 ay boyunca $75 \mathrm{mg}$ klopidogrel oral tablet ve ömür boyu $100 \mathrm{mg}$ asetilsalisilik asit oral tablet kullanımı önerildi. Takip prosedürlerden sonra 3’er aylık sürelerde planlandı. Tüm takip prosedürlerinde DUSG ile infrapopliteal arter akımları değerlendirildi.
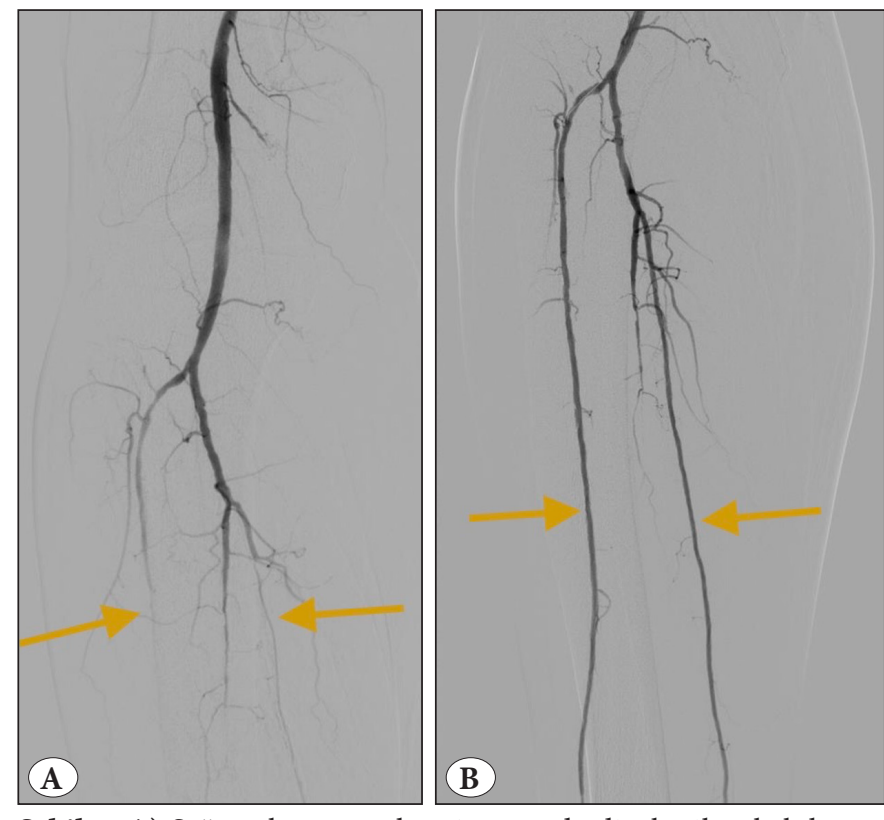

Şekil 1: A) Sağ ayak yarası olan 60 yaşında diyabetik erkek hasta, dijital subtraction anjiografi görüntülerinde verilen kontrast maddenin anterior tibial arter ve posterior tibial arter arterlerinde 3/4 distal segmentine geçmediği görülmekte olup bu düzeyler oklüde görünümdedir. B) Endovasküler transluminal anjioplasti tedavisi sonrası anterior tibial arter ve posterior tibial arter rekanalizasyonu sağlandı ve kontrast madde geçişi ayak bileği dâhil sağlandi.
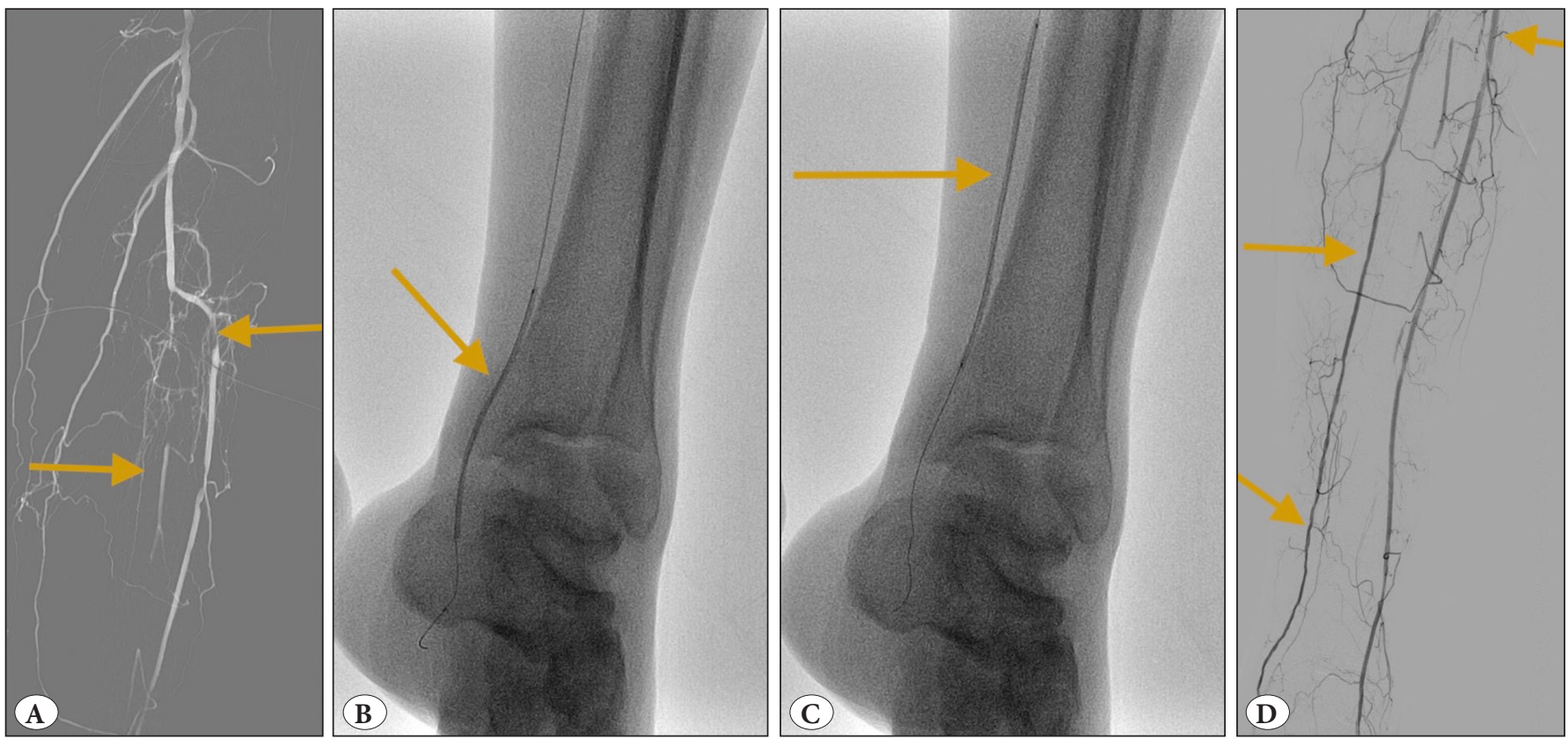

Şekil 2: A) Sol ayak yarası olan 73 yaşında diyabetik erkek hasta, popliteal arterden kontrast madde enjeksiyonu ile alınan roadmap görüntüde posterior tibial arterde kontrast madde dolumu görülmemekte (total oklüde) ve anterior tibial arter proksimal segmentte fokal \% 90 darlık görülmektedir. B,C) Sol ayak posterior tibial artere yönelik uygulanan perkütan transluminal anjioplasti görüntüleri. D) Tedavi sonrası alınan dijital subtraction anjiografi görüntüsünde posterior tibial arterde ve anterior tibial arterde tam rekanalizasyon ve kontrast maddenin tüm ayak boyunca distale geçişi görüldü. 
DUSG sonucunda akım formu darlık göstergesi lehine olan hastalar tanısal ve tedavi amaçlı DSA tetkikine yönlendirildi. Hedef damardaki pik sistolik hız (PSV) belirlendi ve önceki normal segmentteki zirve ile karşılaştırıldı. PSV'de en az $\% 140$ 'lık bir fokal artış o bölgede $>\% 50$ yeniden darlığın göstergesi olarak kabul edildi (8).

\section{İstatistiksel Analiz}

Araştırma verileri "SPSS (Statistical Package for Social Sciences) for Windows 22.0 (SPSS Inc, Chicago, IL)" aracılığıyla bilgisayar ortamına yüklendi ve değerlendirildi. Tanımlayıcı istatistikler ortalama, standart deviasyon ve yüzde olarak sunuldu. Nicel değişkenlerin normal dağılıma uygunluğu görsel (histogram ve olasillk grafikleri) ve analitik yöntemler (Kolmogorov-Smirnov/Shapiro-Wilk Testi) kullanılarak incelendi. İstatistiksel anlamlılık düzeyi $\mathrm{p}<0.05$ olarak kabul edildi.

\section{BULGULAR}

Endovasküler olarak tedavi edilmiş toplamda 19 hasta ve 27 infrapopliteal arter hastalığı verileri çalışmaya dâhil edildi. 13 hasta erkek ve altı kadın, ortalama yaşları 59,43 $\pm 2,41$ yll idi. Hastaların $15(\% 78,9)$ 'inde hipertansiyon, dokuz $(\% 47,3)$ 'unda en az üç yıldır olan diyabet tanısı, yedi $(\% 36,8)$ 'si sigara kullanımı hikayesi vardı. Hastaların 13 $(\% 68,4)$ 'ünde iskemik cilt ülseri, sekiz $(\% 42)$ 'inde istirahat ağrısı mevcuttu. Hastaların tamamında egzersiz ile ağrı semptomu oldu. 11 hastada tek infrapopliteel vasküler lezyon ve sekiz hastada iki infrapopliteal arterde vasküler lezyon mevcuttu. Vasküler lezyonları sinıflandırıldığ 1 zaman $10(\% 37)$ anterior tibial arter, $15(\% 55,5)$ posterior tibial arter, iki $(\% 7,4)$ peroneal arter lezyonu mevcuttur. Uygulanan PTA sonrasi herhangi bir hastada cerrahi müdahale gerektiren majör komplikasyon olmadı.

PTA sonrası alınan kontrol DSA görüntülerinde tedavi teknik başarı oranı \%92,5 (25/27) oldu. Birer infrapopliteal darlığı olan toplam iki hastada tedavi başarısız oldu. Bir yıllık süre boyunca ilk seans tedavi başarılı olan 17 hastanın 25 infrapopliteal arterinin dört infrapoliteal arterinde (üç hasta) nüks darlık nedeni ile ek endovasküler PTA tedavi ugulanması gerekti. Bu üç hasta dört infrapopliteal arterin ek PTA sonrası bir hasta (bir infrapopliteal arter) hariç tamamında bir yıllık süreçte tedavi başarılı oldu. Bir yıllık takip ve tedavi süresi sonrasinda tek seans endovasküler tedavi ile bir yıllık primer patensi oranı \%77,7 (21/27) olarak gerçekleşti. Bu duruma ek seans tedavi uygulanan ve sonrasinda bir yıllık infrapopliteal patensisi devam eden hastalarda bir yıllık sekonder patensi oranı $\% 88.8$ (24/27) oldu. Bir yıllık süre içerisinde hasta sayısı temelinde değerlendirecek olursak bir ylllı primer patensi oranı $\% 73,6$ (14/19), sekonder patensi oranı \%84,2 (16/19) oldu.

\section{TARTIŞMA}

$\mathrm{Bu}$ çalışmada infrapopliteal PAH olan hastalarda endovasküler PTA tedavi bir yıllık takip ve tedavi sonuçları değerlendirildi. Bir yıllık primer patensi oranı $\% 73,6$ (14/19), sekonder patensi oranı \%84,2 (16/19) oldu. Bu sonuçlar ile hasta grubunda etkin bir tedavi yöntemi olduğu bilgisi teyit edildi.

Amerika Birleşik Devletleri'nde, yllda 250.000'den fazla amputasyon gerçekleștirildiği tahmin edilmektedir. $\mathrm{Bu}$ nedenle, alt ekstremite PAH tedavisinde önemli bir amaç uzuv kurtarmadır. Cerrahi veya endovasküler revaskülarizasyon olmadan, kritik ayak iskemisi veya iyileşmeyen ülseri olan hastalar optimal tıbbi tedaviye rağmen sıklıkla amputasyona ilerler (9). Bunun bir kanıtı olarak revaskülarizasyon uygulanmış hastalarda bir yıllık uzuv kurtarma oranına \%75 olarak bildirilmiştir (10). Diyabet PAH riskini iki ila dört kat artırır, daha uzun hastalık süresi ve zayıf glisemik kontrolü olan hastalarda daha büyük risk taşır. Diyabetik hastalarda baskın birikim, arteriyel duvarlar ortaminda hidroksiapatittir. Klinik olarak, intimal kalsifikasyonun plak savunmasızlığına katkıda bulunduğu görülürken, medyada kalsifikasyon, vasküler sertliğe katkıda bulunan hastalık evresinin sonlarına kadar patent lümenli sert kalsifiye damarlarla sonuçlanır. Genel olarak, infrapopliteal hastalık her iki hastalık sürecinin bir kombinasyonudur. Önemli olarak, alt ekstremite PAH olan diyabetik hastalarda diyabetsiz hastalardan beş ila yedi kat daha yüksek ampütasyon riski vardır (11). Bu çalışmada sunduğumuz sonuçlarda endovasküler tedavi uyguladığımız hastalardan herhangi birisinde amputasyon gerçekleşmedi. İnfrapopliteal müdahalenin nihai amacı, uzuv kurtarma için distal ayağa kan akışını artırmak ve yeniden düzenlemektir. Buna ikincil olarak yara iyileşmesi ve semptomların hafiflemesi hedeflenir. İnfrapopliteal hastalığın endovasküler tedavisi hızla gelişmektedir. Son on yılda, medikal tedavi, cihazlar, teknikler ve teknolojideki önemli ilerlemeler bu alanın gelişimine katkıda bulundu. Açık cerrahi ile karşılaştırıldığında, düşük komplikasyon, morbiditeler, amputasyon oranları ve yüksek ekstremite kurtarması ile birlikte iyi bir orta ila uzun vadeli başarı mevcuttur. Ayrıca, endovasküler müdahaleler minimal invaziv yaklaşım olduğu için tedavi sonrası yaşam kalitesi bozulmaz (12). Bu çalışmada infrapopliteal PAH endovasküler PTA tedavisi teknik başarı oranı \%92,5 oldu. Bir yıllık süre içerisinde hasta sayısı temelinde değerlendirecek olursak bir yıllık primer patensi oranı $\% 73,6$, sekonder patensi oranı $\% 84,2$ oldu. Sonuçlarımız kabul edilebilir primer ve sekonder patensi oranına sahiptir. Tedavi edilen damarların küçük çapı ve uzunluğu nedeniyle prosedür kritiktir. Yeniden darlık eğilimi yüksek olduğu için ek endovasküler tedaviler ile sekonder patensi oranının artırılması 
gerekmektedir. Bizim çalışmamızda da ek uygulama ile sekonder patensi oranı iyileştirilmiştir.

PAH olan popülasyonda birçok ek kronik hastalık olduğu için infrapopliteal anjiyoplastinin klinik başarısının sadece teknik başarıya bağlı olup olmadığı açık değildir $(13,14)$. Fakat endovasküler tekniklerin gelişimi endovasküler infrapopliteal revaskülarizasyonda artışa neden olmuştur. Endovasküler tedavi kritik ayak iskemisi olan hastalarda infrapopliteal lezyonlar için revaskülarizasyon stratejisi olarak yaygın hale gelmiştir (15). Balon anjiyoplasti, şiddetli hastalık ve suboptimal rekanalizasyonda bile infrapopliteal hastalık için en uygun endovasküler tedavi yöntemi olmaya devam etmektedir (16).

Primer açıklık oranı ve sekonder açıklık oranı açısından elde ettiğgimiz sonuçlar literatürde bildirilenlerle karşılaşt1rılabilir olduğunu düşünüyoruz. Birçok çalışmayı içeren bir metaanalizde primer açılık oranı $\% 58$-\%74 arasında olduğu bildirilmiştir (17). Tartaglia ve ark. ise tüm vakalarında risk faktörü olarak diyabet bulunmasına rağmen, primer açılık oranı ve sekonder açıklık oranının 1 yılda \%67 ve \%83 olduğunu bildirmiştir (18). Bu çalışmada tedavi uyguladığımız hastalarda diyabet, hipertansiyon, sigara kullanımı gibi PAH yatkınlığını artıran durumlar mevcuttu. Buna rağmen bir yıllık primer patensi oranımız \%73,6 ve sekonder patensi oranımız \%84,2 olmuştur. Patensi oranlarının kabul edilebilir düzeyde olmasının yanısıra, endovasküler tedavinin minimal invaziv olması, hastanın hastenede yatış süresinin kısa olması, aynı gün mobilize olabilmesi gibi avantajları mevcuttur. Ayrıca eğitimli uzmanlar tarafindan uygulandığı zaman komplikasyon oranları oldukça düşük bir yöntemdir.

Çalışmamızın bazı kısıtlılıkları mevcuttur. Birincisi, bu çalışma tek bir merkezde ve nispeten küçük bir çalışma popülasyonu ile gerçekleştirilmiştir. İkincisi, hasta sayısının azlığından dolayı hipertansiyon, diyabet, sigara kullanımı gibi hastalık ve durumların tedavi yanıtına katkı veya dezavantajları değerlendirilemedi.

Sonuç olarak, infrapopliteal PAH hastalarında endovasküler PTA tedavisi düşük komplikasyon ve yüksek patensi oranları ile güvenle kullanılabilir.

Çıkar Çatışması

Makalede sorumlu yazar olarak hiçbir çıkar çatışmam yoktur.

Finansal Destek

Bu çalışma herhangi bir fon tarafından desteklenmemiştir.

\section{KAYNAKLAR}

1. Gray BH, Diaz-Sandoval LJ, et al; Peripheral Vascular Disease Committee for the Society for Cardiovascular Angiography and Interventions. SCAI expert consensus statement for infrapopliteal arterial intervention appropriate use. Catheter Cardiovasc Interv. 2014;84:539-545.

2. Price JF, Mowbray PI, et al. Relationship between smoking and cardiovascular risk factors in the development of peripheral arterial disease and coronary artery disease: Edinburgh Artery Study. Eur Heart J. 1999;20:344-353.

3. Rand T, Uberoi R. Current status of interventional radiology treatment of infrapopliteal arterial disease. Cardiovasc Intervent Radiol. 2013;36:588-598.

4. Aihara H, Soga Y, et al. Comparison of long-term outcome after endovascular therapy versus bypass surgery in claudication patients with TransAtlantic Inter-Society Consensus-II C and D femoropopliteal disease. Circ J. 2014;78:457-464.

5. Söderström MI, Arvela EM, et al. Infrapopliteal percutaneous transluminal angioplasty versus bypass surgery as first-line strategies in critical leg ischemia: A propensity score analysis. Ann Surg. 2010;252:765-773.

6. Thukkani AK, Kinlay S. Endovascular intervention for peripheral artery disease. Circ Res. 2015;116:1599-1613.

7. Lumsden AB, Davies MG, et al. Medical and endovascular management of critical limb ischemia. J Endovasc Ther. 2009;16(2):31-62.

8. Ahn SS, Rutherford RB, et al. Reporting standards for lower extremity arterial endovascular procedures. Society for Vascular Surgery/International Society for Cardiovascular Surgery. J Vasc Surg. 1993;17:1103-1107.

9. Marston WA, Davis SW, et al. Natural history of limbs with arterial insufficiency and chronic ulcerations treated without revascularization. J Vasc Surg. 2006;44:108-114.

10. Wolfe JHN, Wyatt MG. Critical and subcritical ischaemia. Eur J Vasc Endovasc Surg. 1997;13:578-582.

11. Most RS, Sinnock P. The epidemiology of lower extremity amputations in diabetic individuals. Diabetes Care. 1983;6:8791.

12. Kalbaugh CA, Taylor SM, et al. One year prospective quality of life outcomes in patients treated with angioplasty for symptomatic peripheral arterial disease. J Vasc Surg. 2006;44:296-302.

13. Fraser SC, al-Kutoubi MA, et al. Percutaneous transluminalangioplasty of the infrapopliteal vessels: The evidence. Radiology. 1996;200(1):33-36.

14. Conrad MF, Cambria RP, et al. Intermediate results of percutaneous endovasculartherapy of femoropopliteal occlusive disease: A contemporaryseries. J Vascular Surgery. 2006;44:762-769.

15. Shiraki T, Iida O, et al. Predictors of delayed wound healing after endovascular therapy of isolated infrapopliteal lesions underlying critical limb ischemia inpatients with high prevalence of diabetes mellitus and hemodialysis. Eur J Vasc Endovasc Surg. 2015; 49:565-573. 
16. Christenson B, Rochon P, et al. Treatment of infrapopliteal arterial occlusive disease in critical limb ischemia. Semin Intervent Radiol. 2014; 31:370-374.

17. Romiti M, Maximiano M, et al. Meta-analysis of infrapopliteal angioplasty for chronic critical limb ischemia. J Vasc Surg. 2008; 47:975-981.
18. Tartaglia E, Lejay A, et al. Results of isolated infrapopliteal percutaneous transluminal angioplasty for critical limb ischemia in high-risk diabetic patients. Vascular. 2016;24:515522. 